\title{
Educação Superior para Refugiados: uma análise dos procedimentos de ingresso nas universidades brasileiras vinculadas à Cátedra Sérgio Vieira de Mello
}

\author{
Stéfani Rafaela Pintos da Rocha ${ }^{1}$ \\ Rômulo Sousa de Azevedo ${ }^{2}$ (i) \\ Geovana Mendonça Lunardi Mendes ${ }^{1}$ \\ ${ }^{1}$ Universidade do Estado de Santa Catarina (UDESC), Brasil; ${ }^{2}$ Instituto Federal de Goiás (IFG), Brasil
}

Resumo. O presente artigo tem por objetivo compreender como ocorrem as condições de ingresso ao ensino superior para pessoas em condição de refúgio. Para isso, foram analisadas 14 universidades brasileiras, vinculadas à Cátedra Sérgio Vieira de Mello (CSVM), que realizaram ações de acesso para pessoas refugiadas entre os anos 2020-2021. Os dados foram levantados a partir do Relatório Anual da CSVM, e dos sites institucionais das universidades pesquisadas. Trata-se de um estudo descritivo e analítico, com foco em análise documental. O referencial teórico ancora-se nos seguintes autores: Cury (2002), Bobbio (2004), Kreutz (2003) e Moreira (2015) cujas discussões gravitam sobre o direito à educação, políticas educacionais e migração. O estudo nos permite considerar que nem todas as instituições de ensino superior criaram editais específicos ou disponibilizaram vagas exclusivas às pessoas em situação de refúgio ou migração. O ingresso facilitado conforme o relatório da CSVM (2020) tem sido interpretado de diferentes formas pelas instituições de ensino superior, o que denota que nem todas as IES têm garantido o acesso de forma facilitada. Tais dificuldades ocorrem em diversos níveis: desde o acesso à informação para ingresso, a forma de realizar o exame, comprovação de documentos, proficiência em língua portuguesa e pagamento de taxas.

Palavras-chave: refugiados; educação superior; políticas públicas em educação; acesso à educação; pandemia da Covid-19.

Educación superior para refugiados: un análisis de los procedimientos de admisión en las universidades brasileñas vinculadas a la Cátedra Sérgio Vieira de Mello

Resumen. El objetivo del presente artículo es comprender las condiciones de admisión a la enseñanza superior de las personas refugiadas. Para ello se analizaron 14 universidades brasileñas vinculadas a la Cátedra Sérgio Vieira de Mello (CSVM), que tomaron medidas relacionadas con la admisión de personas refugiadas entre los años 2020 y 2021. Los datos se obtuvieron del Relatório Anual da CSVM [Informe anual de la CSVM] y de las páginas web institucionales de las universidades estudiadas. Se trata de un estudio descriptivo y analítico, centrado en el análisis documental. El marco teórico se basa en los siguientes autores: Cury (2002), Bobbio (2004), Kreutz (2003) y Moreira (2015), cuyos argumentos giran en torno al derecho a la educación, las políticas educativas y la migración. El estudio nos permite intuir que no todas las instituciones de educación superior han creado medidas específicas ni han habilitado plazas exclusivas para personas refugiadas o migrantes. Según el informe de la CSVM (2020), las instituciones de enseñanza superior han interpretado la facilitación de acceso de formas distintas, lo que demuestra que no todas ellas han garantizado un acceso facilitado. Dichas dificultades se plantean en varios niveles: desde el acceso a la información de admisión, la forma de realizar el examen, la comprobación de documentos, el dominio de la lengua portuguesa y el pago de las tasas. Palabras clave: refugiados, educación superior, políticas públicas de educación, acceso a la educación, pandemia de Covid-19.

Higher education for refugees: an analysis of admission procedures in brazilian universities related to the Cátedra Sérgio Vieira de Mello

Abstract. This article aims to understand how the conditions for admission to higher education for people in refugee status occur. Therefore, 14 Brazilian universities associated with Sérgio Vieira de Mello Cátedra - CSVM were analyzed. CSVM carried out access actions for refugees between the years 2020-2021. Data was collected from the CSVM Annual Report and from the institutional websites of the surveyed universities. This is a descriptive and analytical study, focusing on document analysis. The theoretical framework is based on the following authors: Cury (2002), Bobbio (2004), Kreutz (2003) and Moreira (2015), whose discussions revolve around the right to education, educational policies, and migration. Based on the analysis, the present study considers that not all higher education institutions launched specific calls for application or made available any exclusive admission process for people in refugee or migration situation. The facilitated admission of refugees and migrants by the CSVM report (2020) has been interpreted in different ways by higher education institutions, which leads to believe that not all universities have guaranteed easy access to that public. Such difficulties occur at different 
levels: from accessing information for admission to knowing how to take exams, proofing of documents, taking proficiency in Portuguese, and paying fees.

Keywords: refugees; higher education; public policies in education; access to education; covid-19 pandemic.

\section{Introdução}

O Brasil é historicamente um país de destino para pessoas de várias nações. Da primeira grande onda migratória iniciada no século XIX, para o arrefecimento da política de migração no século XX, e com um novo aquecimento do movimento migratório no século XXI, principalmente pela presença de grupos oriundos da migração forçada, a presença de imigrantes e refugiados compõem o panorama nacional (Kreutz, 2003).

Por imigrante, nos referimos às pessoas que migram de um país para o outro de forma voluntária, muitas vezes, movidas por melhores oportunidades de trabalho, mas podendo ser também por razões familiares ou de estudos. Ainda assim, mesmo em casos de migração voluntária, isso não significa absolutamente que a pessoa que migra não esteja nesta situação de maneira forçada: ela pode migrar devido a uma crise alimentar em seu país ou por uma situação de extrema pobreza, ou ainda, os casos de migrantes do clima: pessoas que fogem das intempéries climáticas em seus países de origem (Sato, 2020).

No caso do refugiado, a motivação de seu deslocamento ocorre pela via da migração forçada. A pessoa é obrigada a deixar seu país devido a fundados temores de perseguição, que podem ocorrer por motivos de raça, religião, nacionalidade, grupo social, opiniões políticas, ou ainda, devido à grave e generalizada violação de direitos humanos, conforme é regido pelo Estatuto do Refúgio no Brasil, a lei nº 9.474 de 1997. É para esse grupo que nosso olhar se voltará a partir de agora.

Silva et al. (2020) no relatório Refúgio em Números, organizado pelo Observatório das Migrações Internacionais e Ministério da Justiça e Segurança Pública, aponta que de 2011 a 2019 o Brasil recebeu 82.552 solicitações de reconhecimento da condição de refugiado, proveniente principalmente da Venezuela, Haiti, Cuba, China, Bangladesh, Angola e Síria. Referente ao número de refugiados reconhecidos e que vivem no país, o relatório aponta para o quantitativo de 28.702 pessoas, entre 2011 a 2019, com procedência principalmente da Venezuela, Síria, República Democrática do Congo, Líbano, Estado da Palestina, Colômbia e Paquistão.

Estando no país de acolhida, a pessoa em condição de refúgio estará implicada em um processo intersubjetivo de interação com a sociedade de acolhida, conforme afirma Moreira (2015, p. 85) "Entende-se, dessa forma, que assume um caráter dialético, de via dupla: não apenas o refugiado recém-chegado deve se adaptar à comunidade local, como também esta deve se ajustar, abrindo espaço para recebêlo". Ressalta-se com isso, a necessidade da tolerância para com o outro, que traz consigo um repertório cultural, linguístico e religioso próprio, além de carregar em si traços físicos distintos da comunidade de destino" (Moreira, 2015).

O processo de inserção na sociedade se inicia com a chegada da pessoa ao Brasil, onde fará a solicitação de refúgio. Nesse primeiro procedimento ela receberá um protocolo provisório, que cumprirá a função de documento de identidade. Tal documento é importante pois serve de prova da situação regular da pessoa e de que 
está protegida, não podendo ser devolvida para o país de onde saiu. Pelo protocolo ela poderá obter a Carteira de Trabalho e o Cadastro de Pessoa Física. Com esses documentos lhe será possível acessar os serviços públicos disponíveis no Brasil (Acnur, 2015), dentre os quais, a educação.

Se tratando de jovens e adultos, a educação, principalmente de nível superior, supre um papel importante. É a possibilidade que esse grupo tem para escolher uma profissão e a partir do ensino intermediado por experiências em pesquisa, extensão e estágio, atuar no mundo do trabalho. Estudos, ainda incipientes, têm sido realizados para analisar a presença de refugiados na universidade brasileira (Gómez, 2019; Rossa \& Menezes, 2017). Nossa intenção é contribuir para o campo de investigação por meio deste artigo acerca do ensino superior, no que tange a democratização do acesso, permanência e equidade para os sujeitos. Dessa forma, o objetivo deste trabalho é compreender como ocorrem as condições de ingresso ao ensino superior para pessoas em condição de refúgio.

O recorte feito entre 2020 e 2021, considera o período de pandemia da COVID-19. A escolha por esse período se deu primeiro, por se tratar de algo global. É uma situação que não envolve apenas o Brasil, visto que a escala da doença atingiu praticamente todos os continentes. Para se ater apenas ao campo educacional, a UNESCO - Organização das Nações Unidas para a Educação e Ciência, estima que somente em 25 de março de 2020, 184 países fecharam as instituições educacionais - escolas, faculdades e universidades, afetando 1,5 bilhão de alunos. Além disso, a COVID-19 afetou a dinâmica natural do trabalho, estudos, lazer, saúde, ao demandar a criação de políticas públicas para medidas de isolamento social e exigência de equipamentos de proteção, como máscara e uso de álcool em gel (Acnur, 2020). Em relação ao ensino superior, diversos trabalhos foram publicados apontando os impactos da COVID-19 para questões envolvendo o ensino remoto, a baixa interação entre professores e alunos e a predominância de uma racionalidade instrumental (Cerqueira, 2020; Ferreira et al., 2020; Gusso et al., 2020; Pesce \& Hessel, 2021).

Para além dessas questões, no caso de grupos que se encontram em situação de vulnerabilidade, como as pessoas em condição de refúgio, a pandemia pode, também, gerar a perda de oportunidades de aprendizagem devido a entraves de acesso e permanência no ensino superior. É a partir desse cenário que o presente artigo analisa as condições de ingresso ao ensino superior para pessoas em condição de refúgio, no período da pandemia da COVID-19. O recorte aqui apresentado decorre dos interesses de pesquisa dos autores, sendo desenvolvida uma tese de doutorado sobre a temática, além de pesquisas sobre diversidade e educação inclusiva que funcionam como guarda-chuvas para as diferentes pesquisas do grupo.

No âmbito deste estudo, organizamos nossa discussão em três seções: na primeira discutimos o conceito de direito à educação no sistema educacional brasileiro e as políticas educacionais direcionadas ao ensino superior; na segunda seção abordamos o percurso metodológico deste estudo, apresentando as ações da Cátedra Sérgio Vieira de Mello (CSVM) e sua atuação para o acesso de refugiados à universidade brasileira. Na última seção, apresentamos a análise dos dados que tratam das ações de acesso realizadas pelas 14 universidades pesquisadas, encerrando o texto com nossas considerações finais. 


\section{Direito à educação no ensino superior: acesso, permanência e equidade}

Mundialmente, segundo Cury (2002), não há país que se isente da garantia do acesso à educação em seus textos legais. Com base nesse aspecto entende-se que a educação básica é um direito fundamental previsto desde a Constituição Federal de 1988 em seu Cap. 3, Art. 205 , com vistas a preparar a pessoa para o exercício da cidadania, desenvolvimento e qualificação para o trabalho. Esse princípio tem por finalidade garantir a igualdade de condições de acesso e permanência na escola. No entanto, quando aborda o nível superior no Art. $207^{\circ}$, é afirmado que "As universidades gozam de autonomia didático-científica, administrativa e de gestão financeira e patrimonial, e obedecerão ao princípio de indissociabilidade entre ensino, pesquisa e extensão".

No Art. $208^{\circ}$ inciso V, menciona-se o acesso a níveis mais elevados de ensino, sendo este um dever do Estado em garantir e proporcionar políticas públicas para atender não somente a rede regular, no que diz respeito à educação básica em idade obrigatória escolar, mas também investir no ensino superior. Mediante este documento oficial e disparador de outras legislações, vemos que há um movimento e preocupação em proporcionar recursos para garantir a oferta e qualidade do ensino em todas as etapas obrigatórias de escolarização, mas, por outro lado, quando se trata do nível superior este fica a cargo das próprias instituições e de sua autonomia em gerir e organizar os recursos, assim como distribuí-los.

A educação por ser um direito que transita em âmbito internacional e é reconhecido em diferentes documentos legais, necessita ser garantida também em esfera nacional (Cury, 2002). No que tange ao público migrante, estes são amparados pela nova Lei de Migração n. 13.445/2017 na qual em seu Art. $3^{\circ}$ inciso XI, um dos princípios e garantias consiste no acesso igualitário e livre do migrante a serviços, programas e benefícios sociais, bens públicos, educação, assistência jurídica integral pública, trabalho, moradia, serviço bancário e seguridade social. Na concepção de Bobbio, o direito se apresenta como:

[...] uma figura deôntica, portanto, é um termo da linguagem normativa, ou seja, de uma linguagem na qual se fala de normas e sobre normas. A existência de um direito, seja em sentido forte ou fraco, implica sempre a existência de um sistema normativo, onde por "existência" deve entender-se tanto o mero fato exterior de um direito histórico ou vigente quanto o reconhecimento de um conjunto de normas como guia da própria ação. A figura do direito tem como correlato a figura da obrigação. (Bobbio, 2004, p. 36).

Na concepção de Cury (2002), muito do que está escrito na lei entra em conflito com as condições sociais postas diariamente, pois nem sempre o que está prescrito juridicamente é consolidado na prática. Para o autor, "É inegável também a dificuldade de, diante da desigualdade social, instaurar um regime em que a igualdade política aconteça no sentido de diminuir as discriminações". (p.247). No Brasil, a pessoa migrante e em situação de refúgio tem os mesmos direitos assegurados que os nacionais, incluindo o direito à educação, que se respalda na proteção humanitária e jurídica (Goméz, 2019). 
É então pela força de lei que tem ocorrido a democratização do acesso à educação. Mesmo que muitas das ações afirmativas sejam ações paliativas e que não deem conta de resolver as desigualdades sociais, reverberam na formulação, adequação e mobilização das instituições públicas a nível superior a pensarem e desenvolverem internamente a garantia do acesso e permanência dos sujeitos em igualdade de condições.

No entendimento de Cury (2002), o Estado assume o papel de prover e garantir esse direito em igualdade de oportunidades no sentido de contribuir para a redução da desproporcionalidade de acesso e desigualdades referente à renda. As cotas são um dos instrumentos, possibilidade de tornar possível a democratização da educação ao ensino superior para aqueles que são excluídos por não terem as mesmas condições educacionais, econômicas e sociais em relação aos demais. No bojo dessa discussão, a inclusão educacional dos sujeitos em situação de refúgio a partir de políticas de ações afirmativas visa promover a igualdade social em busca de uma agenda por justiça social:

Nesse contexto, a justiça social se consolida na participação popular efetiva no campo político. Nessa acepção, a justiça social é uma questão eminentemente política, e, por consequência, econômica. Isso leva a compreensão de que a política de cotas é também um fato político e econômico, sendo a justiça um meio de justificação para sua adoção, tendo como uma consequência a representação de classes historicamente excluídas e a redução das desigualdades educacionais e sociais. (Souza \& Brandalise, 2017, pp. 524-525).

A igualdade nesse viés se instaura a partir do momento que se consideram as especificidades nas formas de seleção e ingresso ao ensino superior bem como as condições econômicas e sociais dos sujeitos. O nível superior não pode se restringir a uma camada social com privilégios que teve oportunidades, mas garantir que as pessoas de contextos distintos, possam ter as mesmas oportunidades de concorrer a uma prova/exame/concurso. No entanto, para que os grupos socialmente marginalizados possam cada vez mais se inserir nessa modalidade de ensino, é necessário investir também na qualidade da educação escolar básica a fim de ampliar as possibilidades de participação e de ingresso na universidade.

É importante perceber que o direito à educação perpassa todas as etapas e modalidades de ensino, e essa trajetória escolar influencia no acesso ao ensino superior. Para que se efetive na prática é preciso investir também na formação docente, e na qualidade dessa oferta com o intento de consolidar a justiça social. Além dessas questões, outro fator de relevo é a permanência desses sujeitos na universidade já que muitos são oriundos de camadas populares e precisam de auxílio para continuar seus estudos e obterem um desempenho satisfatório.

\section{O recorte metodológico e a Cátedra Sérgio Vieira de Mello como lócus de investigação}

Para esta pesquisa buscamos compreender os procedimentos veiculados por 14 universidades no que se refere ao acesso de pessoas em situação de refúgio ao ensino superior, durante o período de pandemia da COVID-19. Em um primeiro momento, fizemos o levantamento de editais de processo seletivo para refugiados, realizados em 2019 e 2020, com ingresso em 2019 e 2020, e realizados em 2020 
e 2021 com ingresso em 2021. O levantamento foi feito diretamente no site de cada instituição. Caso o procedimento não fosse pela via do edital, pelo site conseguiríamos identificar outras formas desenvolvidas pela instituição para promover o ingresso. Também consultamos via chat e e-mail algumas informações de instituições privadas quando não identificamos o edital ou outra forma de ingresso. Após a busca, fizemos a análise do material a partir das seguintes categorias: comunicação/língua; acesso à informação acerca do processo de ingresso facilitado; análise do edital ou de outro instrumento de ingresso desenvolvido pela instituição.

A Cátedra Sérgio Vieira de Mello é uma ação do Alto Comissariado das Nações Unidas para os Refugiados (Acnur), em cooperação com Instituições de Ensino Superior (IES) brasileiras, públicas e privadas. Por meio deste acordo, as universidades parceiras podem realizar trabalhos em três áreas: pesquisa, ensino e extensão, envolvendo a temática do refúgio. Assim, pela parceria, as IES conveniadas com a CSVM, buscam a consolidação do acolhimento de pessoas em situação de refúgio no meio universitário, e a garantia da coexistência pacífica junto à comunidade local (Acnur, 2020).

Em tempos de pandemia, Cerqueira (2020) relata sua experiência docente realizada de modo remoto, assinalando um aspecto de suma importância, quanto às ações adotadas pelas IES:

É imprescindível que cada universidade tenha o tempo suficiente para deliberar sobre a melhor forma de agir, de modo a garantir um planejamento que compreenda a preparação estrutural, de formação pessoal e da inclusão. Sem esse tempo necessário, arriscaremos um bem importante que é a qualidade do Ensino Superior brasileiro, gratuito e para todos. (Cerqueira, 2020, p.5).

Em se tratando de uma educação para todos, Cury (2002) afirma que é um direito fruto de processos sociais sustentados principalmente pela classe trabalhadora em busca de acesso igualitário:

Aigualdade é o princípio tanto da não-discriminação quanto ela é o foco pelo qual homens lutaram para eliminar os privilégios de sangue, de etnia, de religião ou de crença. Ela ainda é o norte pelo qual as pessoas lutam para ir reduzindo as desigualdades e eliminando as diferenças discriminatórias. (Cury, 2002, p.255).

Essa preocupação em atender com qualidade os estudantes em situação de refúgio pode ser observada no relatório da Cátedra, emitido pelo Acnur em (2020, p. 6), no qual são apresentados os seguintes objetivos da CSVM junto às IES:

Estabelecer rede universitária de apoio às pessoas refugiadas e solicitantes da condição de refugiado em todas as regiões brasileiras, norteada pela promoção de parceria, proteção, qualidade de ensino e facilitação de ingressos à serviços de apoio e ao ensino acadêmico;

Sensibilizar, capacitar e contribuir para a formação de professores e estudantes universitários acerca das três vertentes da Proteção Internacional da Pessoa Humana visando a sensibilização e o ensino sobre o tema do refúgio; Incentivar a pesquisa, a produção de conhecimento científico e difusão de trabalhos acadêmicos, fortalecendo a construção e o compartilhamento de saberes entre os universitários; 
Incorporar prestação de serviços às pessoas refugiadas, por meio do atendimento solidário e promoção de serviços comunitários a essa população nas IES e em suas áreas de abrangência.

Para este artigo, iremos nos ater ao primeiro objetivo, que trata do ingresso às pessoas em condição de refúgio a partir das ações realizadas pelas universidades conveniadas com a CSVM entre 2020 a 2021. No mesmo relatório nos é apresentado que, até agosto de 2020, havia 23 IES em parceria com a CSVM, conforme consta no quadro abaixo:

Quadro 1. Instituições parceiras da Cátedra Sérgio Vieira de Mello.

IES conveniadas com a CSVM, até agosto de 2020

1. Universidade Federal de Roraima - UFRR

2. Universidade Estadual da Paraíba - UEPB

3. Universidade Federal do Espírito Santo - UFES

4. Universidade Federal de Velha - UVV

5. Fundação Casa de Rui Barbosa - FCRB

6. Universidade Federal Fluminense - UFF

7. Pontifícia Universidade Católica do Rio de Janeiro - PUC-RJ

8. Universidade do Estado do Rio de Janeiro - UERJ

9. Universidade Católica de Santos - UNISANTOS

10. Universidade Federal do ABC - UFABC

11. Pontifícia Universidade Católica de São Paulo - PUC-SP

12. Universidade Estadual de Campinas - UNICAMP

13. Universidade Federal de São Paulo - UNIFESP

14. Universidade Federal de São Carlos - UFSCAR

15. Universidade Federal de Santa Catarina - UFSC

16. Universidade do Vale do Itajaí - UNIVALI

17. Universidade do Vale do Rio dos Sinos - UNISINOS

18. Universidade Federal do Rio Grande do Sul - UFRGS

19. Universidade Federal de Santa Maria - UFSM

20. Universidade Federal do Paraná - UFPR

21. Universidade Federal da Grande Dourados - UFGD

22. Pontifícia Universidade Católica de Minas Gerais - PUC-MG

23. Universidade de Brasília - UNB

Fonte: Elaboração dos autores com os dados do Relatório Anual da Cátedra Sérgio Vieira de Mello (ACNUR, 2020).

Nesse primeiro quadro observa-se a extensão do convênio entre a CSVM e as universidades brasileiras. Há ações de ensino, pesquisa e extensão em todas as regiões do país: Norte, Nordeste, Centro-Oeste, Sudeste e Sul. O que esse dado indica? Primeiro, que o tema do refúgio é um tema nacional. Não se restringe a um estado ou município, mas abrange o país. Se há universidades de todas as regiões conveniadas com a CSVM, é porque esse é um tema presente em suas respectivas localidades. Segundo a importância de se tratar do refúgio nas universidades. Uma 
vez que o tema é interdisciplinar, pode ser abordado em diversos campos: Direito, Medicina, Letras, Pedagogia, Enfermagem, Relações Internacionais, Ciências Sociais, Assistência Social, dentre outros.

Em relação ao ingresso facilitado, o relatório da Acnur apresenta a seguinte definição:

O ingresso facilitado ao ensino superior é uma iniciativa das IES que levam em consideração a situação de vulnerabilidade das pessoas refugiadas e, assim, disponibilizam vagas exclusivas para refugiados, refugiadas, solicitantes da condição de refúgio e/ou migrantes em situação de vulnerabilidade. (Acnur, 2020, p. 12).

Dessa forma, o procedimento de ingresso facilitado envolve mudanças no sistema de acesso ao ensino superior, que permite às pessoas em situação de refúgio ou migrantes em situação de vulnerabilidade, ter acesso aos cursos ofertados pelas instituições públicas e privadas com vagas exclusivas, com um processo que considera suas particularidades e especificidades. O relatório aponta ainda que entre 2019 e 2020, 14 universidades realizaram o procedimento de ingresso facilitado para graduação e pós-graduação: UNISANTOS, UFGRS, UVV, PUC-Minas, UNIFESP, UFPR, UFSM, UFF, UFSCAR, UNICAMP, UNB, UFES, UEPB e UFABC. Um total de $62 \%$ das 23 instituições parceiras da CSVM. Das 14 universidades, 11 realizam o procedimento de ingresso através de edital exclusivo para refugiados e migrantes em situação de vulnerabilidade. Ao todo, 383 vagas foram ofertadas para pessoas refugiadas e solicitantes de refúgio nos cursos de graduação.

É então a partir desse grupo de 14 universidades (considerando tanto as universidades que realizaram o procedimento de ingresso via edital, como aquelas que utilizaram outros instrumentos) que analisamos os dados que tratam das ações de acesso para pessoas em condição de refúgio, no período da pandemia da COVID-19.

Adiferença de nossa pesquisa para o Relatório da Cátedra é, então, não apenas apresentar as ações realizadas em 2020, mas incluir também aquelas já realizadas no ano de 2021. Além disso, no relatório consta as ações de forma mais resumida, até mesmo pela proposta do documento, no entanto, para nossa pesquisa, iremos nos ater a detalhes importantes para a compreensão de nosso objeto de estudo, como será apresentado a partir de agora.

\section{O ingresso "facilitado" é mesmo "facilitado"?: a realidade do processo de ingresso dos refugiados nas IES estudadas}

Apresentamos no quadro abaixo as universidades que desenvolveram mecanismos considerados pelo Relatório da CSVM como ingresso facilitado para refugiados.

\section{Quadro 2. Universidades vinculadas à CSVM.}

Forma de acesso/ingresso

\section{UNISANTOS}

(Privada)

Edital $\mathrm{n}^{\circ}$.

$01 / 2020$

https://bit.

Bolsa de estudos, sem taxa de inscrição, inscrição via e-mail ou presencial, site com acessibilidade no idioma da língua inglesa. Prova não traduzida em outro idioma, mesma seleção para todos os candidatos.

$\underline{\mathrm{ly} / 3 \mathrm{KKskIC}}$ 


\begin{abstract}
UFRGS
(Pública)

Não dispõe de acessibilidade linguística no site, assim como o edital. Inscrição

Edital $\mathrm{n}^{\circ}$ presencial, sem taxa de inscrição. Critério de seleção definido por cada curso

$1 / 2019$ em 4 formas: entrevista, carta de intenções, prova escrita e prova prática.

https://bit. Iy/3o0Rsdz Em cada forma de seleção é definido o critério de escrita no idioma nacional ou estrangeiro. Exige proficiência do candidato em língua portuguesa se for aprovado na seleção.

UVV

(Privada)

https://uvv.br/

NUARES - Núcleo de apoio a Refugiados no Espírito Santo. Site não dispõe de acessibilidade linguística. Não foram encontradas informações, entre 2019 e 2021, acerca dos instrumentos de ingresso para o público refugiado.
\end{abstract} editais/

PUC-MINAS

(Privada)

https://www. pucminas.br/ vestibular/Paginas/default. aspx

\section{UNIFESP \\ (Pública) \\ Edital $n^{\circ}$ \\ 26/2019 \\ https://bit. Iy/3AwrC6G}

\section{UFPR}

(Pública)

Edital $\mathrm{n}^{\circ}$ 85/2019

https://bit. $\underline{\text { Iy/3r1VXad }}$
Site não dispõe de acessibilidade linguística. Não foi identificado processo seletivo específico para refugiados. Para ingressar na universidade, o candidato, em processo seletivo simplificado de ampla concorrência, pode fazer uso da nota do ENEM ou uma redação online que precisa ser agendada. O resultado é divulgado em até 72 horas após realização da redação ou 24 horas após a inscrição pela nota do ENEM. A matrícula também ocorrerá à distância, logo após a divulgação do resultado. É cobrada uma taxa de inscrição no valor de $\mathrm{R} \$ 35,00$ para participar do processo seletivo. Entramos em contato pelo chat da instituição para mais informações: o candidato fará uma redação com a possibilidade de ser avaliado em sua língua, mas as aulas serão ministradas em português, sendo assim é necessário o entendimento da língua.

Site não dispõe de acessibilidade linguística. Processo seletivo gratuito, sem cobrança de taxa. Inscrição via requerimento eletrônico. É exigida documentação comprobatória da situação de mobilidade/deslocamento. Não exigem a tradução da documentação comprobatória. Publicam os resultados com o nome dos candidatos. Seleção por prova objetiva e uma prova de redação. A redação deve ser escrita em língua portuguesa. A prova objetiva é fornecida em língua portuguesa. Será considerado habilitado o candidato que tenha obtido notas maiores que zero em cada prova e, ainda, obtiver nota final igual ou superior a 30 (trinta). Para os discentes ingressantes por meio deste processo seletivo será ofertada a possibilidade de realização de curso de aprimoramento em português (ou equivalente) pela UNIFESP e/ou parceiros. Em qualquer fase do procedimento, e ainda após o efetivo ingresso, o interessado perderá o vínculo com a UNIFESP, se não confirmada sua permanência legal no país.

Site não dispõe de acessibilidade linguística, assim como o edital. Edital específico para migrantes em condição de refugiado ou com visto humanitário. Processo seletivo gratuito, sem cobrança de taxa. Foram disponibilizadas dez vagas suplementares nos cursos de graduação, sem restrição de cursos. A inscrição foi realizada no site da instituição. É exigida documentação comprobatória da situação de mobilidade/deslocamento. Publicam os resultados com o nome dos candidatos. São concedidas condições especiais a candidatos com necessidades especiais: auditiva, física, motora, visual ou múltipla, ou ainda com distúrbios de aprendizagem, desde que se apresente comprovação por laudo médico. Seleção por prova objetiva e uma prova de redação. A redação deve ser escrita em língua portuguesa. A prova objetiva é fornecida em língua portuguesa. 
Universidade

UFSM

(Pública)

Edital $\mathrm{n}^{\circ}$

$001 / 2018$

https://bit. Iy/3KNTFTR

Forma de acesso/ingresso

Site não dispõe de acessibilidade linguística, assim como o edital. O edital regulamenta o Programa de Acesso à Educação Técnica e Superior na UFSM para Refugiados e Imigrantes em situação de vulnerabilidade. De acordo com este edital, será reservado o percentual de até $5 \%$ de vagas do número total de vagas/ingresso ofertadas em cada curso (Técnico, Tecnológico e de Graduação), mediante a aprovação do respectivo Colegiado de Curso, dessa forma, a seleção ocorre por cada Colegiado. A solicitação de escolha de curso pelo refugiado, pode ser feita pelo seu idioma. Este edital ficou em vigência entre 09 de janeiro a 02 de Março de 2018. Não foram encontrados no site da instituição, editais de anos seguintes. Como confirmação dessa informação, foi identificado no site uma notícia que informa a suspensão do programa de ingresso, desde 2018. A notícia é do dia 04 de março de 2020: https://www. ufsm.br/cursos/pos-graduacao/santa-maria/ppgd/2020/02/10/a-politica-deingresso-e-permanencia-de-migrantes-e-refugiados-na-ufsm-e-debatida-emoficina-do-migraidh-csvm-na-jai/.

UFF

(Pública)

https://www. uff.br/?q=tags/

Não foi encontrado no site da instituição, editais ou outras formas de ingresso para refugiados aos cursos de graduação entre os anos de 2020 e 2021.

refugiados

UFSCAR

(Pública)

Edital $\mathrm{n}^{\circ}$

007/2019

https://bit. ly/3GOYqWM

Edital $\mathrm{n}^{\circ}$

005/2020

https://bit. Iy/3tZMCBC

Site sem acessibilidade linguística, assim como o edital. Processo seletivo gratuito, sem cobrança de taxa. No edital de 2019, com ingresso em 2020, as inscrições deveriam ser encaminhadas por correio. No edital de 2020, com ingresso em 2021, considerando a pandemia da COVID-2019, as inscrições passaram a ser efetuadas por formulário eletrônico. É exigida documentação comprobatória da situação de mobilidade/deslocamento. Os editais disponibilizam uma vaga em cada opção de curso. Não houve prova, a classificação dos candidatos foi realizada pelo resultado do Exame Nacional do Ensino Médio - ENEM. Os nomes dos candidatos foram preservados na publicação do resultado, utilizando-se o número de inscrição.

Site com acessibilidade linguística em inglês, espanhol, dentre outros idiomas. O processo de ingresso ocorre por análise de documentos na Diretoria Acadêmica da Instituição. Para solicitar uma vaga, o candidato deve preencher um formulário com informações pessoais e apresentar uma carta com

\section{UNICAMP}

(Pública)

https://www.

dac.unicamp. br/portal/ estude-na-unicamp/vaga-para-refugiados breve histórico de vida, mas não é especificado em qual língua a carta deve ser redigida. Subentende-se que deve ser escrita em português. Além disso, deve ser apresentada uma certidão expedida pelo CONARE que comprove a condição de refugiado, e a Carteira de Registro Nacional Migratório. No caso da documentação escolar, esta deve ser de conclusão de estudos equivalentes ao Ensino Médio, com parecer de equivalência emitido pela Secretaria de Estado da Educação. Caso não seja possível apresentar esses documentos, a universidade abre para a possibilidade do candidato apresentar outros meios de prova da conclusão do Ensino Médio. Após o envio, os documentos serão analisados por uma Comissão de Avaliação. Em caso de deferimento, a Instituição entrará em contato com o candidato para informar sobre os trâmites de matrícula. No site é explícito que não há vagas garantidas. Será levado em consideração a análise da documentação entregue e o limite máximo de estudantes que cada curso possibilita. 
Site com acessibilidade linguística em inglês e espanhol. O processo de aceitação do candidato ocorre por avaliação do Colegiado de Curso, conforme Resolução $n^{\circ} 64$ de 2007 do Conselho de Ensino, Pesquisa e Extensão, da UNB referida universidade. A resolução consta somente em português. As vagas (Pública) para refugiados são disponibilizadas a partir de vagas ociosas decorrentes de https://bit. desligamento, transferência de estudantes para outras IES ou remanescentes Iy/3fVChyo do vestibular. O refugiado poderá obter vaga na UNB através desse processo somente uma vez. A Resolução não oferece informações mais detalhadas, para isso, o candidato precisa entrar em contato com o Decanato de Ensino de Graduação.

Site com acessibilidade linguística. Conforme as informações no site da universidade, as pessoas interessadas precisam protocolar o pedido na Pró-Reitoria de Graduação (PROGRAD). Durante o período da pandemia, o procedimento foi realizado pelo e-mail drca.prograd@ufes.br. Para a inscrição, os candidatos

UFES

(Pública) têm que apresentar o comprovante de conclusão do ensino médio emitido pelo

Resolução $\mathrm{n}^{\circ}$ $66 / 2010$ país de origem - em português ou com tradução simples - e um documento de identidade com foto que comprove sua situação de refugiado ou solicitante de https://bit. ly/33SnZMC refúgio, e também informar o nome do curso de interesse.

Segundo a Resolução $n^{\circ}$ 66/2010 do Conselho de Ensino, Pesquisa e Extensão (Cepe) da instituição, que define as normas para o ingresso de refugiados aos cursos da Universidade, cabe à PROGRAD enviar os pedidos aos colegiados dos cursos requeridos, para análise, seleção e decisão. Os colegiados têm a tarefa de determinar o número de vagas destinadas, garantindo o mínimo de uma vaga por curso.

UEPB

(Pública)

https://bit. ly/3rY7cQq
Site não dispõe de acessibilidade linguística. O ingresso dos estudantes em situação de refúgio será por meio das vagas remanescentes disponibilizadas pela Pró-Reitoria de Graduação (PROGRAD). Conforme notícia no site da Universidade em novembro de 2019 , além da distribuição das vagas, a PROGRAD também se responsabilizou pela elaboração do edital e processo seletivo. A Universidade adota $100 \%$ da nota do Sistema de Seleção Unificada (SISU) obtida pelo Exame Nacional do Ensino Médio (ENEM).

Site com acessibilidade linguística em inglês. Conforme o edital $n^{\circ} 13 / 2021$, a UFABC estabeleceu ação afirmativa própria reservando vagas para Refugiados e solicitantes de refúgio. As vagas são subtraídas daquelas da modalidade UFABC denominada de Ampla Concorrência. Em conformidade com a Resolução do (Pública) Conselho Universitário (CONSUNI) $n^{\circ} 182$, ficam reservadas 2 (duas) vagas por Edital $n^{\circ} \quad$ curso, para refugiados e solicitantes de refúgio. Metade do número de vagas 13/2021 disponível em edital, será reservada para refugiados e solicitantes de refúgio https://bit. $\underline{\mathrm{ly} / 3 \mathrm{KK} 8 \mathrm{Q} x h}$ com renda familiar bruta igual ou inferior a 1,5 salário mínimo per capita. Os candidatos convocados para a matrícula deverão apresentar documentação comprobatória do Comitê Nacional para os Refugiados (CONARE) ou apresentação do protocolo de solicitação de refúgio, de acordo com os procedimentos que regulamenta a Lei $n^{\circ}$ 9.474/1997.

Fonte: Elaborado pelos autores (2021).

Conforme exposto no quadro 2, os procedimentos de ingresso facilitado variam conforme a interpretação de instituição para instituição, o que torna o sistema complexo, pois não há uma uniformização das ações. A comprovação da situação migratória, por exemplo, exigida pelas universidades para a matrícula dos candidatos, não é um 
procedimento padronizado. Em uma instituição identificamos que foi solicitada uma dentre cinco alternativas de documentos: Registro Nacional de Estrangeiros (RNE); Carteira de Identidade de Estrangeiro (CIE); Carteira de Registro Nacional Migratório (CRNM); Atestado expedido pelo Comitê Nacional para Refugiados (CONARE); Passaporte. Nesse sentido, a diversidade de documentos é importante pois possibilita a participação de um maior número de pessoas, observando que, após a nova lei migratória, de 2017, o CRNM substituiu os demais documentos, assim, quem não possui este documento, mas possui o RNE ou o CIE não seria impedido de realizar o processo seletivo.

No entanto, em outras instituições, a comprovação da documentação de mobilidade/deslocamento, se dava somente pela apresentação do atestado expedido pelo CONARE, o que pode se tornar um entrave. No edital $n^{\circ} 007 / 2019$ da UFSCAR, houve 09 inscrições de pessoas em situação de refúgio, mas apenas 03 foram homologadas. Das 06 não homologadas, 04 inscrições envolveram a não apresentação da certidão emitida pelo CONARE. No edital $n^{0}$ 005/2020 da mesma universidade, houve 12 inscrições, mas apenas uma foi homologada. Das 11 não homologadas, 10 inscrições envolveram a não apresentação da certidão emitida pelo CONARE. O que esse dado significa? Que diferentes formas de exigência de documentação reduzem o acesso de alguns candidatos. É necessário haver aquilo que Rossa e Menezes (2017) chamam de sensibilidade administrativa, que é acompanhada pela flexibilidade, pela consideração da condição especial dos refugiados e pelo que é preconizado na lei $n^{0}$ 9.474/1997.

As disponibilidades de vagas também se alternam para cada instituição. Em uma IES identificamos que em determinado edital, foram disponibilizadas dez vagas para os 120 cursos da instituição. Os cursos disponíveis se limitam a esse quantitativo. Apesar de não fazer restrição a determinados cursos - o aluno poderia cursar desde uma licenciatura, engenharia ou medicina - o quantitativo de vagas é pequeno diante da oferta de opções, o que diminui também o alcance para que mais pessoas tenham acesso ao ensino superior pela universidade.

Em outras universidades, o procedimento se concentra em ofertar uma vaga em cada curso, e ainda em outras, o quantitativo de vagas se decide a partir de uma comissão avaliativa que define o número máximo de alunos permitidos por cursos, ou então, pela avaliação de colegiados de cada área. Soma-se a esse conjunto, as universidades que disponibilizam vagas para refugiados a partir da ociosidade, desligamento e transferência de estudantes para outras instituições. Nesse último caso em específico, tal procedimento torna o ingresso fragilizado, pois além de não disponibilizar vagas para todos os cursos, infere-se que aquelas áreas com maiores procuras, como as áreas de engenharia ou saúde, por exemplo, podem não disponibilizar vagas caso não haja ociosidade, desligamento ou transferência.

Outro ponto a se observar é a preservação da identidade das pessoas. Considerando que a busca por refúgio se pauta na migração forçada (Brasil, 1997), a preservação de suas identidades nos países de destino é algo necessário, inclusive para garantir a essas pessoas uma maior segurança e proteção. Nos editais de vestibular de três universidades em que foram publicados os resultados, duas divulgaram 
os nomes dos candidatos. Uma solução seria apresentar os resultados pelo número de inscrição de cada pessoa, como feito pela UFSCAR, nos editais de ingresso de 2020 e 2021.

É importante ainda, destacar a acessibilidade no acesso às informações. Como a pessoa em situação de refúgio chega ao país não falando a língua, e leva-se um período para que ela desenvolva o domínio linguístico, seria necessário que as IES disponibilizassem informações acerca dos procedimentos de ingresso facilitado em outras línguas, como inglês, francês e espanhol. Nesse sentido, nos referimos principalmente a sites, editais e resoluções. Sobretudo, a língua, mesmo antes da pessoa realizar a prova, já se torna um critério eliminatório ao desconsiderar casos de pessoas que estejam no país há menos tempo (Rossa \& Menezes, 2017). Com maior acessibilidade linguística, pode-se aumentar o alcance das informações para mais pessoas, e dúvidas podem ser sanadas por disponibilizar o documento na língua de origem do candidato ou o site da instituição oferecer opção de leitura em outro idioma.

Além disso, pensando para além do ingresso, é importante investigar como as universidades têm trabalhado a questão do apoio linguístico como política de ação afirmativa para essa população. Em muitos países, as universidades subsidiam programas para que os ingressantes tenham condições de acompanhar o curso e paralelamente possam desenvolver competências linguísticas. No caso do Brasil, Rossa e Menezes (2017) apontam que um caminho possível é que as universidades invistam em projetos extensionistas de ensino de português, de forma que os refugiados tenham condições de progredir nos cursos matriculados. Das universidades pesquisadas, identificamos que a UNIFESP desenvolve algo semelhante, com curso de aprimoramento em português para novos alunos, o que não significa que outras instituições não desenvolvam o mesmo projeto, mas que apenas identificamos tal ação na referida universidade.

Cabe salientar ainda que além do acesso, é necessário pensar como garantir a permanência dos estudantes, que em muitos casos não têm condições econômicas para concluir os estudos. Tal situação, interfere no rendimento e continuidade da pessoa que está em situação de vulnerabilidade social. Por isso, Souza e Brandalise (2017, p. 517) destacam a necessidade de:

[...] uma democratização do ensino, possibilitando o fortalecimento do acesso, mas, principalmente, a permanência do estudante nesse nível de ensino. Tais condições que são, muitas vezes, negadas pela realidade social, necessidades como alimentação, transporte, moradia e aproveitamento educacional, tornamse questões que inviabilizam a permanência de estudantes beneficiados por tais políticas.

Destacamos ainda que algumas universidades não criaram edital específico para o público em situação de refúgio ou migração, mas apenas realizaram instruções no site. Outras IES deslocaram a responsabilidade do processo seletivo para que cada centro dos cursos de graduação crie o próprio edital de seleção, com exigências específicas, como carta de intenção, entrevistas e comprovação de proficiência em língua portuguesa. 
Das 14 instituições vinculadas à CSVM, 3 são privadas (UNISANTOS, UVV e PUC-MINAS) e 11 públicas (UFRGS, UNIFESP, UFPR, UFSM, UFF, UFSCAR, UNICAMP, UNB, UFES, UEPB e UFABC). As instituições de cunho privado não desenvolvem editais, utilizam o processo seletivo tradicional. Nas instituições públicas, essa realidade destoa. Deparamos com algumas universidades que oferecem vagas remanescentes, outras criam editais específicos, e ainda outras se valem da nota do Sistema de Seleção Unificada (SISU) dos participantes que realizam o ENEM, ou dos colegiados de cada curso.

Há então, vários desafios para a democratização do acesso ao ensino superior e sua consolidação nas IES. Rossa e Menezes (2017, p.6), afirmam que "Não obstante tais iniciativas e garantias, o acesso ao ensino superior [...] está longe de ser um direito plenamente acessado por refugiados no Brasil, na verdade, esse é um dos grandes empecilhos para sua integração à sociedade".

Podemos mesmo afirmar que há um choque entre a lei e as adversas condições sociais que regem a sociedade. Como consequência, surgem entraves que dificultam o acesso efetivo dos refugiados ao ensino superior. Pontua-se com isso que reside no direito à educação uma dimensão de luta, um campo de disputas, em torno de efetivações mais realistas e a construção de gerações mais iguais (Cury, 2002).

\section{O difícil do fácil: os diversos desafios a serem vencidos no acesso ao Ensino Superior}

Ao sistematizarmos as universidades que realizaram procedimentos de ingresso facilitado, tendo como linha temporal os anos de 2020 e 2021, identificamos, a partir do Relatório da Cátedra Sérgio Vieira de Mello, edição de 2020, 14 universidades entre públicas e privadas, que realizaram alguma ação nesse sentido. Em termos quantitativos, chamamos atenção para o alto número de instituições envolvidas e a diversidade de regiões às quais são oriundas, como as regiões centro-oeste, sudeste, sul e nordeste.

Em termos qualitativos, identificamos que o ingresso facilitado é variado, alternando seu modelo de instituição para instituição. A variação ocorre desde a forma de ingresso, que pode ser via edital com provas objetivas ou apenas redação; colegiado de curso; e disponibilidade de vagas ociosas; até a forma de comprovar documentação, tanto de refúgio como de estudos, que também difere de cada IES.

Devido a essa variedade de formas de ingresso, o sistema se torna complexo, pois a depender da instituição em que o candidato participe da seleção, o acesso pode ser mais ou menos facilitado. Por exemplo, apesar da maioria das instituições não realizarem cobrança para participar do ingresso ou taxa de matrícula, identificamos que em uma IES é cobrado um valor para a participação no processo seletivo. Se a pessoa em condição de refúgio mora ali e não tem condição de se deslocar para outra IES que não tenha cobrança de taxa, cabe a ele/a apenas aquela opção, e caso não tenha condições financeiras, fica impossibilitada de participar do processo. Diante disso, podemos até mesmo questionar o que determina um ingresso ser facilitado ou não. 
Para que o ingresso ao ensino superior possa alcançar mais pessoas em condição de refúgio, inferimos que determinadas áreas do procedimento possam ser padronizadas, em especial: a não cobrança para participar de processos seletivos e para efetivar matrícula; acessibilidade linguística em sites, resoluções e editais; uniformização na solicitação de documentos escolares e migratórios. Com a padronização, amplia-se a possibilidade da pessoa em condição de refúgio ingressar no ensino superior, ao passo que as universidades obtêm mais informações e orientações quanto a forma de coordenar seus próprios processos.

Pontuamos ainda a necessidade de dar aos próprios refugiados, o espaço para o diálogo com os demais atores envolvidos, algo enfatizado por Moreira (2015). É imperativo ouvir suas perspectivas acerca das dificuldades na realização dos processos de ingresso e efetivação da matrícula, se tornando um caminho viável para o aprofundamento da efetividade do programa.

Considerando o que foi exposto até o momento, destacamos que as formas de ingresso em uma IES nem sempre foram acessíveis, com entraves que impedem um ingresso facilitado de fato. Algo percebido através de exigências distintas aos candidatos, como: entrevistas; carta de intenção; cobrança de taxa; proficiência em língua portuguesa ainda na seleção; solicitação de documentos diversos; ausência de acessibilidade linguística em sites, editais e resoluções; em alguns casos, vagas condicionadas à desistência e ociosidade de cursos menos elitizados, estimados, o que nos induz a pensar na exclusão e na dificuldade de ascensão e de representatividade do público em situação de refúgio em áreas mais elevadas ou na ocupação de cargos mais promissores, ou seja, vemos a influência do capital quando observamos a manutenção da desigualdade social, à medida que exclui e determina em que cursos essas pessoas podem ou não ingressar; e identidade não preservada na apresentação do resultado do processo seletivo.

Diante dos dados apresentados, percebemos que o ingresso facilitado posto pelo Acnur (2020) em seu relatório anual, tem se mostrado como um percurso de muitos embates. Claro, não devemos desconsiderar os avanços conquistados pela Cátedra e as universidades conveniadas, no que tange aos processos de integração dos refugiados nas mais diversas áreas e dimensões da sociedade (Moreira, 2015). No entanto, é necessário pontuar que referente ao ingresso facilitado, há ainda barreiras que devem ser superadas. O estudo nos mostra que estamos em um processo inicial de democratização do acesso à universidade para pessoas em situação de refúgio. Ainda há muito por fazer, e tais experiências vivenciadas precisam constantemente ser analisadas para que possamos evoluir na promoção de equidade educacional nessa etapa do ensino.

\section{Agradecimentos}

O presente trabalho foi realizado com apoio da Coordenação de Aperfeiçoamento de Pessoal de Nível Superior - Brasil (CAPES) - "Código de Financiamento 001". 


\section{Referências}

Acnur (2015). Cartilha para Solicitantes de Refúgio no Brasil. [eletrônico]. Local de publicação: editor. Disponível em https://bit.ly/3fJt4sO.

Acnur (2020). Relatório Anual - Cátedra Sérgio Vieira de Mello. Disponível em: https://bit.ly/3nD1Atp. Bobbio, N. A. (2004). Era dos direitos. Rio de Janeiro: Elsevier.

Brasil (1988). Constituição da República Federativa do Brasil: texto constitucional promulgado em 5 de outubro de 1988, com as alterações determinadas pelas Emendas Constitucionais de Revisão nos 1 a 6/94, pelas Emendas Constitucionais nos 1/92 a 91/2016 e pelo Decreto Legislativo no 186/2008. Brasília: Senado Federal, Coordenação de Edições Técnicas. 496 p. ISBN: 978-85-7018-698-0. Disponível em https://bit.ly/3IIVBRD.

Brasil (1997). Lei $n^{\circ}$ 9.474, de 22 de julho de 1997. Define mecanismos para a implementação do Estatuto dos Refugiados de 1951, e determina outras providências. Diário Oficial da União, Brasília. Disponível em http://www.planalto.gov.br/ccivil_03/Leis/L9474.htm.

Cerqueira, B. R. S. de. (2020). Educaçãono Ensino Superior em Tempos dePandemia. OlhardeProfessor, 23, 1-5. https://doi.org/10.5212/OlharProfr.v.23.2020.16175.209209226867.0616.

Cury, C. R. J. (2002). Direito à educação: direito à igualdade, direito à diferença. Cadernos de Pesquisa, 116, 245-262. Disponível em https://bit.ly/3fHg5rG.

Ferreira, D. H. L., Sugahara, C. R. e Branchi, B. A. (2020). O impacto da COVID-19 no ensino superior: desenvolvimento de atividades remotas em matemática e estatística. Revista Tecnologia e Sociedade. 16(43) 138-146. https://doi.org/10.3895/rts.v16n43.12209.

Goméz, M. V. (2019). Ações da universidade brasileira para abrir a educação a pessoas em situação de refúgio. Cadernos CERU. 30(1) 96-134. https://doi.org/10.11606/issn.2595-2536. v30i1p96-134.

Gusso, H. L., Archer, A. B., Luiz, F. B., Sahão, F. T., Luca, G. G. D., Henklain, M. H. O., ... e Gonçalves, V. M. (2020). Ensino superior em tempos de pandemia: diretrizes à gestão universitária. Educação \& Sociedade, 41, 1-27. https://doi.org/10.1590/ES.238957

Kreutz, L. (2003). A educação de imigrantes no Brasil. In: Lopes, E. M. T., Faria Filho, L. M. e Veiga, C. G. 500 anos de educação no Brasil. $3^{\mathrm{a}}$ ed. Belo Horizonte: Autêntica.

Moreira, J. B. (2015). O papel das Cátedras Sérgio Vieira de Mello no processo de integração local dos refugiados no Brasil. Monções. Revista de Relações Internacionais, 4(8), 81-96. Disponível em https://bit.ly/3fIFJfC.

Pesce, L. e Hessel, A. M. di G. (2021). Ensino Superior no Contexto da Pandemia da COVID-19: Um relato analítico. Revista Práxis Educacional, 17(45) 1-19. https://doi.org/10.22481/ praxisedu.v17i45.8323.

Rossa, L. A. e Menezes, M. A. de. (2017). Imigração e refúgio no Brasil e os programas especiais de acesso ao ensino superior: levantamentos iniciais dos programas implementados até 2016. Encontro Nacional sobre Migração (10). Disponível em: https://bit.ly/357Hhhk.

Sato, M.(org.). (2020). Os condenados da pandemia. Cuiabá: GPEA-UFMT.

Silva, G. J., Cavalcanti, L., Oliveira, T. e Macedo, M. (2020). Refúgio em Números, $5^{a}$ ed. Observatório das Migrações Internacionais; Ministério da Justiça e Segurança Pública/ Comitê Nacional para os Refugiados. Disponível em https://bit.ly/3Ae9IWl.

Souza, A. C. de, e Brandalise, M. Â. T. (2017). Política de cotas e democratização do ensino superior: a visão dos implementadores. Revista Internacional de Educação Superior 3(3), 515-538. https://doi.org/10.22348/riesup.v3i3.7763.

\section{Como citar em APA:}

Rocha, S. R. P. da, Azevedo, R. S. de \& Mendes G. M. L. (2022). Educação Superior para Refugiados: uma análise dos procedimentos de ingresso nas universidades brasileiras vinculadas à Cátedra Sérgio Vieira de Mello. Revista Iberoamericana de Educación, 88(1), 147-162. https://doi. org/10.35362/rie8814828 